\title{
The use of botulinum toxin $A$ in chemical component separation: a review of techniques and outcomes
}

\author{
Sharbel A. Elhage, Eva B. Deerenberg, Jenny M. Shao, Vedra A. Augenstein, B. Todd Heniford \\ Department of Gastrointestinal and Minimally Invasive Surgery, Carolinas Medical Center, Charlotte, NC 28204, USA.
}

Correspondence to: Dr. B. Todd Heniford, Department of Gastrointestinal and Minimally Invasive Surgery, Carolinas Medical Center, 1025 Morehead Medical Drive, Suite 300, Charlotte, NC 28204, USA. E-mail: todd.heniford@gmail.com

How to cite this article: Elhage SA, Deerenberg EB, Shao JM, Augenstein VA, Heniford BT. The use of botulinum toxin A in chemical component separation: a review of techniques and outcomes. Plast Aesthet Res 2020;7:16.

http://dx.doi.org/10.20517/2347-9264.2020.03

Received: 3 Jan 2020 First Decision: 12 Mar 2020 Revised: 18 Mar 2020 Accepted: 26 Mar 2020 Published: 10 Apr 2020

Science Editor: Sahil Kuldip Kapur Copy Editor: Jing-Wen Zhang Production Editor: Tian Zhang

\begin{abstract}
Fascial closure is crucial for abdominal wall reconstruction (AWR) but can be especially difficult in patients with massive ventral hernias or loss domain. Recently, botulinum toxin A (BTA) has been increasingly utilized as an adjunct in AWR to aid in fascial closure. This review aims to evaluate the current literature on the use of BTA in AWR to assess current treatment regimens, side effects, outcomes and complications. A literature search was performed, yielding 10 studies that met the inclusion criteria. There was a significant amount of heterogeneity in treatment regimens, with studies differing in BTA injection timing, dosage, concentration, and location. The majority of studies showed that injection of BTA preoperatively was able to augment abdominal wall musculature, with many showing a decrease in mean transverse defect size and high rates of successful fascial closure. No major complications were reported from BTA administration, with only mild side effects reported by some studies. The most common side effects include a weak cough or sneeze, bloating, and back pain, which generally all resolved prior to surgery. While BTA appears to be a promising adjunct for AWR, further investigation is needed to determine optimal patient selection and treatment regimens.
\end{abstract}

Keywords: Hernia, abdominal wall reconstruction, botulinum toxin, botox, chemical component separation

\section{INTRODUCTION}

Ventral hernias are a frequent complication after open abdominal surgery and up to $30 \%$ develop incisional hernias ${ }^{[1-3]}$. Repair of incisional hernias is difficult due to scarring and the distortion of tissue planes innate to a reoperative field. In complex cases, such as massive hernias, those with loss of domain, recurrent hernias, or hernias with infection or contamination, patient morbidity can be greatly increased.

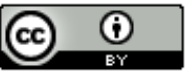

(C) The Author(s) 2020. Open Access This article is licensed under a Creative Commons Attribution 4.0 International License (https://creativecommons.org/licenses/by/4.0/), which permits unrestricted use, sharing, adaptation, distribution and reproduction in any medium or format, for any purpose, even commercially, as long as you give appropriate credit to the original author(s) and the source, provide a link to the Creative Commons license, and indicate if changes were made.

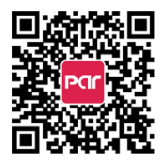


Despite advances in mesh technology, refinement of surgical techniques, and the advent of myofascial reconstruction techniques, abdominal wall reconstruction (AWR) in these patients is still associated with high rates of recurrence ${ }^{[4-6]}$. In addition, each failed attempt at hernia repair results in higher morbidity, costs, and risk of recurrence for each subsequent repair ${ }^{[7,8]}$.

An especially challenging patient population for hernia specialists is those with loss of domain. This occurs when an abdominal wall defect progresses to a size at which it may no longer accommodate the abdominal viscera, leading to irreducible protrusion into the hernia sac. Chronic muscle retraction reduces the volume of the peritoneal cavity and precludes tension-free fascial closure during AWR, with potential problems such as abdominal compartment syndrome, ventilatory restriction, and an elevated risk of hernia recurrence. In hernia defects over $8.3 \mathrm{~cm}$ in width, component separation is often needed to achieve primary, tension-free fascial closure ${ }^{[9]}$. Other techniques that have been utilized to increase the abdominal domain in large hernias with loss of domain include progressive pneumoperitoneum and soft tissue expanders. These are not without risk of morbidity however ${ }^{[10,11]}$.

More recently, preoperative injection of botulinum toxin A (BTA) has been added to the surgeon's armamentarium for AWR as an off-label use. BTA is a neurotoxin produced by the bacterium Clostridium botulinum, which has been shown to have a variety of therapeutic uses through its inhibitory effect on presynaptic cholinergic nerve terminals ${ }^{[12]}$. Treatment of a muscle with BTA results in functional denervation within 2 days and with peak effect after 4-6 weeks, leading to flaccid paralysis. This has been successfully used for several ocular and facial nerve disorders, as well as a range of other neuromuscular disorders including laryngeal, cervical and hand dystonia ${ }^{[12]}$. The first experimental study reporting the benefits of BT and its application in abdominal wall repair was published by Cakmak et al ${ }^{[13]}$ In a rat study, they demonstrated increased abdominal wall laxity after BTA injection in the lateral abdominal wall. The amount of intraperitoneal saline required to reach a fixed intraabdominal pressure after BTA administration was significantly higher than before treatment with BTA. The neurotoxin BTA results in a form of chemical component separation, causing relaxation of the lateral muscles of the abdominal wall. The first report of preoperative injection of BTA for AWR was by Ibarra-Hurtado et al. ${ }^{[14]}$ in 2009, where BTA was used to facilitate fascial closure in 12 patients. The lateral muscle paralysis achieved, and transverse hernia defect reduction in size, allowed for closure with minimal tension. BTA might also decrease pain after AWR and the need for narcotic analgesia. Besides blocking the release of acetylcholine, BTA also prevents release of the pain-modulating molecules calcitonin gene-related peptide and substance P from the presynaptic motor nerve terminal ${ }^{[15]}$.

The following review aims to summarize the literature regarding the clinical use of BTA in AWR, and assess the varying regimens, published effects, outcomes, and complications reported.

\section{METHODS}

A literature review was performed using the PubMed Medline database. The following search and keyword techniques were used: [(“botulinum") AND ("hernia") NOT ("paraesophageal" OR "esophageal" OR "hiatal" OR "diaphragmatic" OR "disk”)]. We limited our review to studies written in English.

Our search yielded 47 articles, and 10 met our inclusion criteria for review ${ }^{[14,16-24]}$. Two independent reviewers assessed the articles for inclusion. Studies that did not report outcomes of preoperative BTA use in AWR for ventral hernia were excluded. We also excluded review articles, case reports, cadaveric studies, and studies on groin hernias.

Two BTA products were utilized in the 10 studies included for analysis - onabotulinum toxin A (Botox Allergan, Dublin, Ireland) and abobotulinum toxin A (Dysport ${ }^{\circ}$, Ipsen, Boulogne-Billancourt, France). 

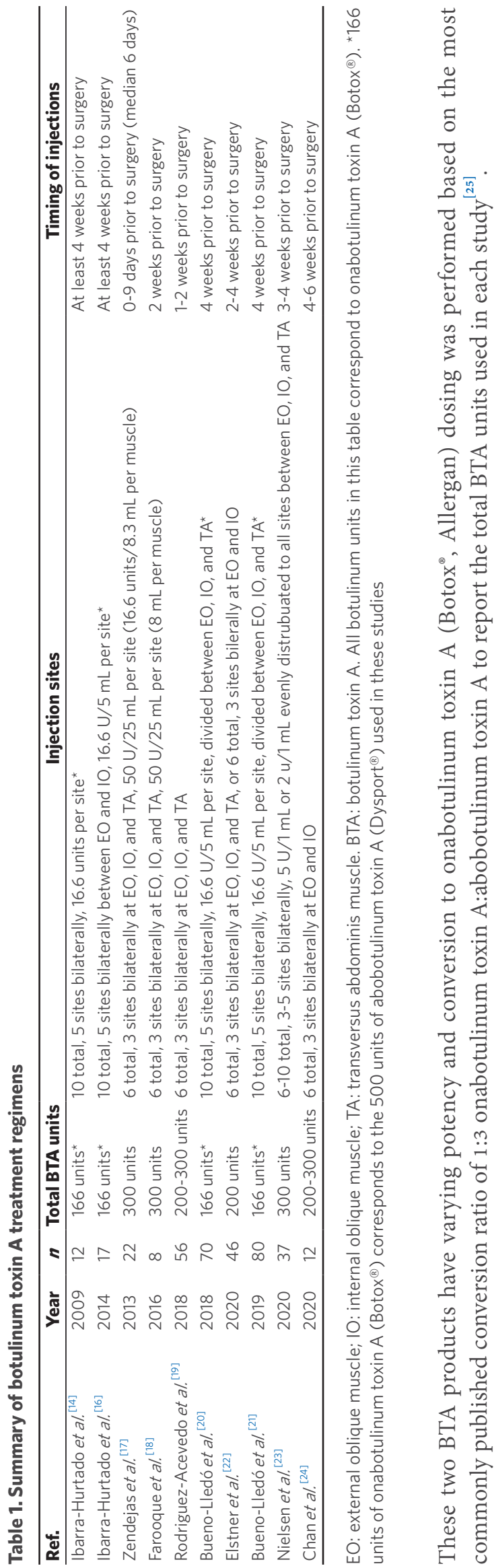

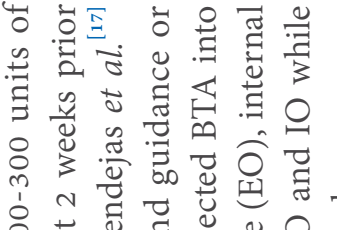

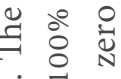

官

กิ

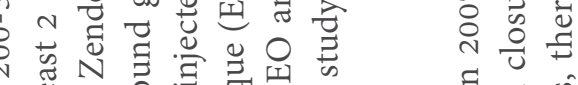

o

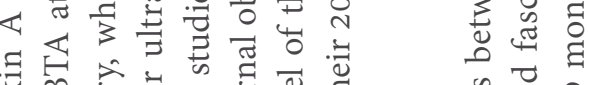

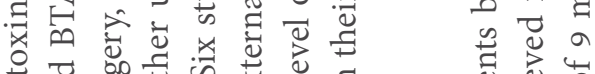

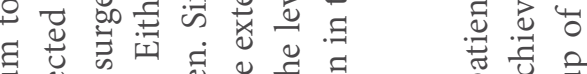

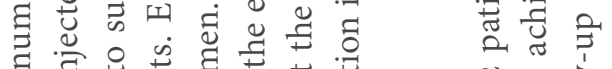

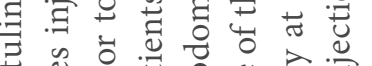

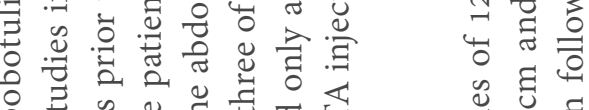

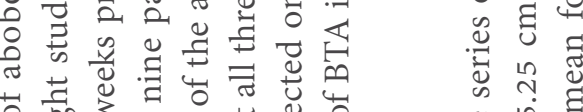

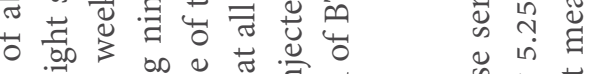

党

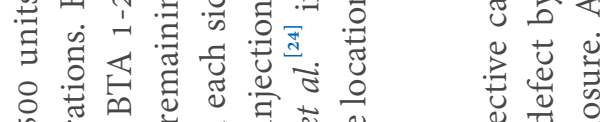

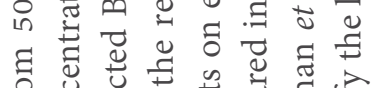

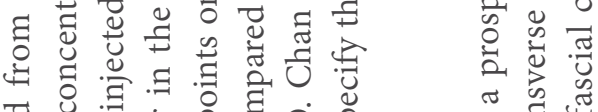

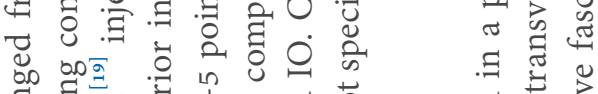

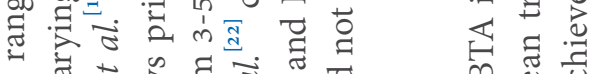

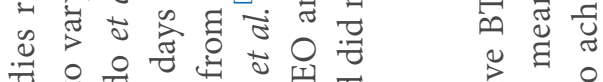

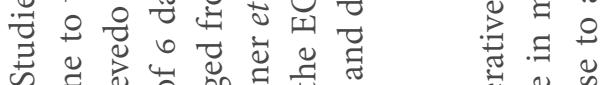

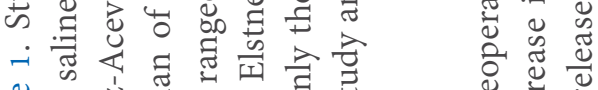

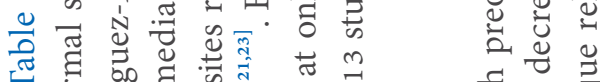

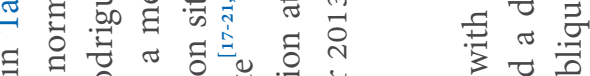

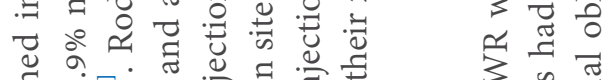

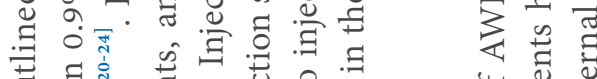

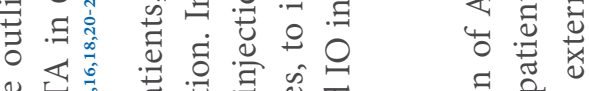

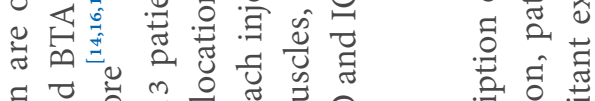

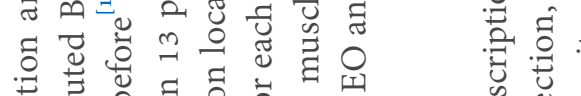

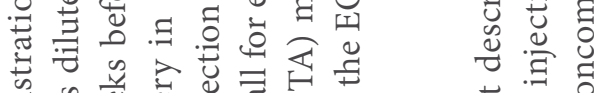

की

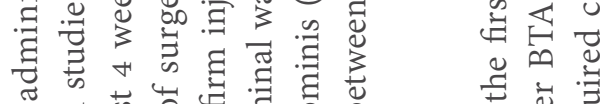

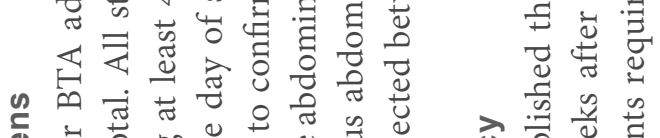

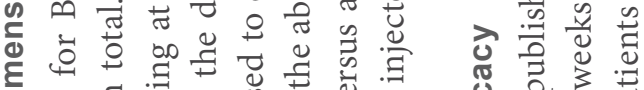

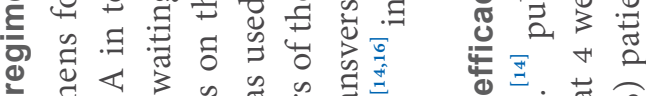

《.

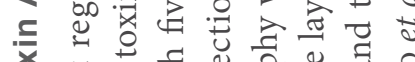

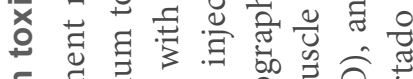

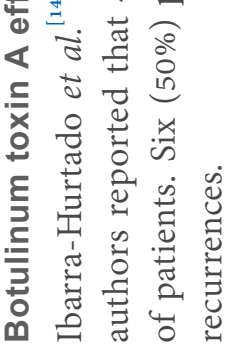


The same group then conducted another prospective study of a series of 17 patients between 20092011. These patients were all males with midline ventral hernias who were at least 12 months out from laparotomy and open abdomen without formal abdominal closure. On CT scans performed 4 weeks after BTA injection, statistically significant decreases in bilateral muscular thickness and length, and transverse hernia defect sizes (all $P<0.0001$ ) were found. As with their prior study, the authors were able to achieve fascial closure in $100 \%$ of patients, with nine patients (53\%) requiring additional EO release. Similarly, no recurrences developed at a mean follow-up of 49 months ${ }^{[16]}$.

Reporting on a series of 22 patients, Zendejas et al. ${ }^{[17]}$ evaluated BTA use in AWR and its effect on postoperative pain control in 2010. These 22 patients received preoperative BTA injections and were matched to 66 controls based on age, sex, BMI, number of hernia recurrences and type of hernia repair. Thirteen (59\%) of the patients in the BTA group received injections on the day of surgery, while the remaining nine had injections on an average of 6 days preoperatively. They found that the BTA group used $44 \%$ less morphine equivalents on hospital day two and $64 \%$ less on hospital day five, while reporting significantly lower pain scores at both time points (all $P<0.05$ ). Hernia size was only reported in $73 \%$ of patients with an average of $59.7 \mathrm{~cm}^{2}$ in the BTA group vs. $117.5 \mathrm{~cm}^{2}$ in the control. While there was no statistically significant difference between the two groups, this clinical difference may have played a role in the results. In the BTA group, $54.6 \%$ of cases were completed laparoscopically and fascia was only reapproximated in $40.9 \%$ of patients. No difference in the rates of component separation, length of stay, or recurrence between the two groups was found at a mean follow-up of 18 months.

Farooque et al. ${ }^{[18]}$ described a prospectively collected series of eight patients from 2012-2013 who underwent AWR with preoperative BTA injections. All patients were considered complex, having had at least two prior hernia repairs, with defect sizes ranging from $5 \mathrm{~cm} \times 9 \mathrm{~cm}$ to $24 \mathrm{~cm} \times 24 \mathrm{~cm}$, and an $11 \mathrm{~cm}$ mean transverse defect size. On post-BTA imaging, a decrease in the thickness of the abdominal wall musculature by an average of $6.3 \mathrm{~mm}$, and a decrease in abdominal wall muscle length by an average of $2.8 \mathrm{~cm}$ per side was noted. All hernia repairs were performed laparoscopically with intraperitoneal onlay mesh (IPOM) placement. Fascial closure rates and long term outcomes were not reported however.

In a prospective case series of 56 patients from 2012-2017, Rodriguez-Acevedo et al. ${ }^{[19]}$ evaluated patients with complex ventral hernias who received BTA 1-2 weeks prior to AWR. They defined complex hernias as recurrent or traumatic hernias having a minimum defect width of $6 \mathrm{~cm}$, and/or loss of domain greater than $20 \%$. They also reported a mean transverse defect size of $11.6 \mathrm{~cm}$ prior to BTA administration. Defects ranged from $5 \mathrm{~cm} \times 9 \mathrm{~cm}$ to $28 \mathrm{~cm} \times 19 \mathrm{~cm}$. In addition to BTA, patients with a transverse defect size greater than $15 \mathrm{~cm}$, and infraumbilical defect greater than $9 \mathrm{~cm}$, or loss of domain greater than $20 \%$ (18/56 patients) received preoperative progressive pneumoperitoneum (PPP) of up to $1000 \mathrm{cc}$ for 3-7 days before surgery. Patients averaged an increase in abdominal wall muscle length of $4.0 \mathrm{~cm}$ per side, with no statistical difference between those receiving 200 and 300 units of BTA. No statistical difference in muscle length gain between the patients receiving BTA alone vs. those receiving BTA plus PPP was reported. Fascial closure was achieved in $100 \%$ of patients, with eight (14\%) requiring component separation. Fiftythree patients had a laparoscopic or laparoscopic assisted repair with intraperitoneal mesh placement, and the remaining three patients had open repairs with retro-rectus mesh placement. At 26 months post-repair, there was one case of recurrence but the overall mean follow-up period was not reported.

Publishing the largest series thus far with 70 patients, Bueno-Lledó et al. ${ }^{[21]}$ reported a retrospective case series of prospectively collected data on patients who received BTA 4 weeks prior to AWR from 20102016. All patients also received 500-1000 cc of PPP for 1-2 weeks prior to surgery. Using CT imaging before and after administration of BTA and PPP, they calculated volume of the hernia (VIH) and volume of the abdominal cavity (VAC). The VIH:VAC ratio decreased by an average of $16.6 \%$ after administration of BTA 
and PPP $(P=0.02)$ but there was no significant difference in median transverse or longitudinal hernia defect size. Fascial closure was achieved in $95.7 \%$ of patients using a variety of techniques: $54(77.1 \%)$ external oblique release, $14(20 \%)$ transversus abdominis release, and $2(2.9 \%)$ retro-rectus repairs. Mesh was used in all patients. At a mean follow-up of 34.5 month, 4 recurrences (5.7\%) were reported ${ }^{[20]}$. In 2019, the authors updated their series with 10 more patients with overall data showing a similar reduction in VIH:VAC ratio (16.3\%), fascial closure (96.3\%) and recurrence rates (6.2\%) with a mean follow-up of 38.5 months.

In the only study comparing BTA injection techniques, Elstner et al. ${ }^{[22]}$ evaluated a total of 46 patients in a prospective, observational fashion from 2015-2018. They compared two consecutive cohorts: 23 patients received $\mathrm{BTA}$ at three sites bilaterally, targeting each muscle of the abdominal wall (EO, IO, TA) at each injection site, and 23 patients who also received the same, but only targeting the EO and IO. Age, BMI, transverse defect size, and number of failed hernia repairs were similar in both groups. Using serial CT imaging, there was no difference in abdominal wall length gain between the groups $(P=0.37)$. All patients underwent laparoscopic or laparoscopic-open-laparoscopic hernia repair with IPOM. Fascial closure rate was $100 \%$, and there were no recurrences at mean follow-up of 24 months. They concluded that BTA injection of the TA can be omitted without compromising fascial closure in complex ventral hernias.

Nielsen et al. ${ }^{[23]}$ retrospectively evaluated the short-term safety of BTA for the treatment of large hernias in 37 patients from two centers. The mean defect width was $12.1 \mathrm{~cm}$, and $33(89.2 \%)$ patients had no prior hernia operations. All patients underwent open repair with $95 \%$ being retro-muscular. Component separation was used in 15 (40.5\%) patients and fascial closure was achieved in $100 \%$ of cases. Six patients required readmission within 30 days however, three for wound complications. In total, nine patients developed wound related complications. Outcomes beyond 30 days and recurrence rates were not reported.

In the most recent study by Chan et al. ${ }^{[24]}, 12$ patients underwent preoperative BTA injections prior to hernia repair. On CT imaging after BTA, there was a statistically significant increase in both left $(P=0.004)$ and right $(P=0.014)$ sided mean abdominal wall lengths, with an increase in mean abdominal wall length of $4.0 \pm 2.2 \mathrm{~cm}$ per side. Nine patients underwent laparoscopic repair with IPOM, and one patient had a robotic IPOM repair. The remaining two patients underwent laparoscopic-open-laparoscopic repair, one with IPOM and the other with a retro-rectus mesh placement. Based on the description of the "Venetian Blinds" surgical technique used, it appears that fascia was reapproximated in all patients although this was not directly reported. No hernia recurrences at a median follow-up of 18.3 months was observed.

\section{Complications and side effects of botulinum toxin A}

Nine of ten studies in our review reported on specific BTA related complications or side effects ${ }^{[16-24]}$. Five did not have any complications or side effects related to BTA administration ${ }^{[16,17,20,21,24]}$ while the remaining four reported side effects without major complications ${ }^{[18,19,22,23]}$.

Nielsen et al. ${ }^{[23]}$ reported one patient (2.7\%) who had pain related to BTA injections. This was managed without narcotic pain medications and resolved prior to surgery.

The remaining three studies shared a common theme of patients reporting a weak cough or sneeze following BTA administration ${ }^{[18,19,22]}$. Farooque et al ${ }^{[18]}$ found that in patients experiencing these symptoms, this improved with application of an abdominal binder, and all resolved prior to surgery.

Rodriguez-Acevedo et al ${ }^{[19]}$ found that several patients developed superficial bruising at the BTA injection sites. In addition to the weak cough, patients also reported a sensation of bloating that resolved only after the hernia repair. Four patients in their study also reported back pain after BTA injections but with unclear duration. For these complaints, an abdominal binder again proved to manage symptoms adequately. 
This study included 18 patients who also received PPP, but because data on which patients developed these complications was not reported, it is not certain these symptoms can be attributed solely to BTA administration.

Elstner et al. ${ }^{[22]}$ did not report any complications related to BTA administration but do describe similar side effects of weak cough and sneeze, and a sensation of bloating. Patients also described back pain, and one experienced dyspnea. Similarly, abdominal binders were found to aid in symptom resolution. The authors theorized that sparing the TA from BTA injection may allow for increased core stability and reduction of these side effects. However, they no statistical analysis was performed to compare the three muscle layer group and the EO and IO only group regarding these side effects.

\section{DISCUSSION}

Improving outcomes of AWR in large hernias starts with optimization of modifiable patient factors, such as weight loss, smoking cessation and controlling diabetes. Furthermore, to reduce complication and recurrence rates, the goal of AWR should be achievement of primary fascial closure with mesh reinforcement, instead of bridging the hernia defect with mesh ${ }^{[26]}$. Both increased intrabdominal pressure, as well as morbid obesity which is associated with increased intrabdominal pressure, may play a role in the development of hernias and hernia recurrences ${ }^{[27]}$. Different component separation techniques can be used to increase abdominal cavity volume and decrease intrabdominal pressure, but this necessitates destruction of the anatomical tissue planes of the abdominal wall ${ }^{[28,29]}$. The use of BTA as a chemical rather than surgical technique for components separation achieves abdominal wall compliance by elongation and thinning of the musculature, although such application is currently off-label ${ }^{[16]}$.

While there are relatively few studies evaluating the efficacy of BTA in AWR, and no randomized controlled trials, the existing evidence remains promising. Studies evaluating abdominal wall muscle thickness and length were able to show significant differences after administration of $\mathrm{BTA}^{[16,18-22,24]}$. As would be expected with these effects on the musculature, many studies then showed a decrease in the mean transverse defect size. In studies reporting fascial closure, all but one achieved very high success rates after pre-operative BTA. Zendejas et al. ${ }^{[17]}$ reported a low fascial closure rate in their BTA patients (40.9\%), but this was not dissimilar from their propensity matched control group (36.4\%). This raises the question of whether this lower fascial closure rate reflects surgeon preference and surgical technique as opposed to BTA treatment effect. Three studies, including the largest review to date by Bueno-Lledó et al. ${ }^{[20,21]}$, used PPP as an adjunct to BTA in AWR, which makes extrapolation of results to patients receiving BTA only difficult ${ }^{[19]}$. Further limitations of this review include the significant amount of heterogeneity in regard to hernia characteristics, surgical techniques, and the type of mesh used. While BTA appears to be an effective adjunct therapy in AWR, none of the studies in this review detailed the selection criteria and hernia characteristics that may define patients who would benefit most from BTA injection.

There is significant variation in technique, number of sites and timing of injection in the reviewed articles. Functional denervation starts after 2 days and the effect peaks at approximately 2 weeks after BTA injection and lasts beyond 30 days $^{[12,30]}$. Injection at least 2 weeks prior to surgery seems most beneficial for AWR. Ultrasound guidance appears sufficient for targeted BTA injection and was used in all but one study. Guidance techniques should be based on the comfort of the provider however ${ }^{[16-24]}$. All studies injected at least the EO and IO, with most injecting the TA as well. Theoretically, paralysis of all 3 layers of the lateral abdominal wall could interfere with the stabilizing function of the core abdominal muscles, potentially contributing to back pain and predisposing to injury, as hypothesized by Elstner et al ${ }^{[22]}$ However, in large ventral hernias, this stabilizing function is likely already impaired due to disruption of the midline. If this is a concern in patients with pre-existing conditions, application of an abdominal binder or selective injection 
of the EO and IO can be performed, sparing the TA and its truncal stabilizing function. Elstner et al. ${ }^{[22]}$ found comparable results of two and three layer BTA injection in laparoscopic hernia repair. A total of at least 200 BTA units at a concentration of $2 \mathrm{U} / \mathrm{mL}$ or more was used in all studies. Since there is great heterogeneity in timing, sites and total BTA units injected in the studies, no conclusion on the optimal dose, concentration, sites, or target muscle layer(s) can be formulated. Furthermore, one study which assessed abdominal wall effects of BTA with both functional CT and EMG at 1-4 weeks after injection showed non-uniform distribution and duration of the induced paralysis ${ }^{[31]}$.

BTA has also been shown to prevent release of the pain-modulating molecules calcitonin gene-related peptide and substance $\mathrm{P}$ from the presynaptic motor nerve terminal and could have a positive effect on postoperative pain control ${ }^{[15]}$. One study reported on post-operative pain and found promising results with decreased morphine use and pain reported in the short-term postoperative period. Nevertheless, the analgesic effects of BTA would benefit from further research ${ }^{[17]}$.

With the introduction of new medications for clinical use, patient safety is of utmost importance. The majority of studies did not report complications with the use of BTA and of those that did, they were minor in nature. Complaints after BTA injection included a mild cough or sneeze, bloating, and back pain, and nearly all resolved after application of an abdominal binder. However, serious adverse effects of BTA injection can occur and have been described after administration at other sites of the body. These adverse effects are often related to the specific injection site, non-sterile injection technique, or injection into infected tissue ${ }^{[32]}$. Four cases of life-threatening botulism have occurred after injection of highly concentrated, unlicensed preparation of BTA for cosmetic purposes ${ }^{[33]}$. Although the precise human lethal dose of crystalline BTA is not known, extrapolation from primate studies suggest an approximate intravenous or intramuscular lethal dose of $40 \mathrm{U} / \mathrm{kg}$ of BTA in humans ${ }^{[34,35]}$. Therefore, for an average $70 \mathrm{~kg}$ human, the lethal dose would be 2800 units in total; in AWR, the maximum reported total dose used is 300 units of BTA, which is drastically lower than the described lethal dose. Proper storage of the product, selection of the correct dose, and proper administration techniques are necessary to prevent these adverse events when injecting BTA into the abdominal wall. Patients with neuromuscular junction disorders such as myasthenia gravis, Lambert-Eaton syndrome, and anterior horn disorders are particularly susceptible to the adverse events of botulinum toxin and should not be injected with BTA ${ }^{[32]}$.

\section{CONCLUSION}

The initial results of BTA use in AWR are promising and safe, with beneficial alterations to the abdominal wall and high rates of fascial closure, and only minor side effects reported. There remains much variance in BTA treatment regimens and at this time, a consensus on the dosage, technique, and timing of injection has yet to be reached. There remains a lack of high-level evidence and the existing literature is limited by studies with small sample sizes, unclear patient selection criteria, and treatment regimen heterogeneity.

\section{DECLARATIONS}

\section{Authors' contributions}

Made substantial contributions to conception and design of the study and performed data analysis and interpretation: Elhage SA, Deerenberg EB, Shao JM, Augenstein VA, Heniford BT

Performed data acquisition, as well as provided administrative, technical, and material support: Elhage SA, Deerenberg EB, Shao JM

Drafting of manuscript and critically important revisions: Elhage SA, Deerenberg EB, Shao JM, Augenstein VA, Heniford BT

\section{Availability of data and materials}

Not applicable. 


\section{Financial support and sponsorship}

None.

\section{Conflicts of interest}

Dr. Heniford has received honoraria, speaker's fees, and research support from Allergan, W. L. Gore, and Stryker. Dr. Augenstein has received honoraria and speaker's fees for Allergan, Intuitive, Acelity, W. L. Gore, and Medtronic. The remaining authors have no other relevant financial or personal relationships that could inappropriately influence this work or its conclusions.

\section{Ethical approval and consent to participate}

Not applicable.

\section{Consent for publication}

Not applicable.

\section{Copyright}

(C) The Author(s) 2020.

\section{REFERENCES}

1. Kingsnorth A, LeBlanc K. Hernias: inguinal and incisional. Lancet 2003;362:1561-71.

2. Deerenberg EB, Harlaar JJ, Steyerberg EW, Lont HE, van Doorn HC, et al. Small bites versus large bites for closure of abdominal midline incisions (STITCH): a double-blind, multicentre, randomised controlled trial. Lancet 2015;386:1254-60.

3. Jairam AP, Timmermans L, Eker HH, Pierik REGJM, van Klaveren D, et al. Prevention of incisional hernia with prophylactic onlay and sublay mesh reinforcement versus primary suture only in midline laparotomies (PRIMA): 2-year follow-up of a multicentre, double-blind, randomised controlled trial. Lancet 2017;390:567-76.

4. Weissler JM, Lanni MA, Tecce MG, Carney MJ, Shubinets V, et al. Chemical component separation: a systematic review and meta-analysis of botulinum toxin for management of ventral hernia. J Plast Surg Hand Surg 2017;51:366-74.

5. Deerenberg EB, Timmermans L, Hogerzeil DP, Slieker JC, Eilers PH, et al. A systematic review of the surgical treatment of large incisional hernia. Hernia 2015;19:89-101.

6. Luijendijk RW, Hop WC, van den Tol MP, de Lange DC, Braaksma MM, et al. A comparison of suture repair with mesh repair for incisional hernia. N Engl J Med 2000;343:392-8.

7. Flum DR, Horvath K, Koepsell T. Have outcomes of incisional hernia repair improved with time? A population-based analysis. Ann Surg 2003;237:129-35.

8. Heniford BT, Park A, Ramshaw BJ, Voeller G. Laparoscopic repair of ventral hernias: nine years' experience with 850 consecutive hernias. Ann Surg 2003;238:391-9.

9. Blair LJ, Ross SW, Huntington CR, Watkins JD, Prasad T, et al. Computed tomographic measurements predict component separation in ventral hernia repair. J Surg Res 2015;199:420-7.

10. Mayagoitia JC, Suárez D, Arenas JC, Díaz de León V. Preoperative progressive pneumoperitoneum in patients with abdominal-wall hernias. Hernia 2006;10:213-7.

11. Wooten KE, Ozturk CN, Ozturk C, Laub P, Aronoff N, et al. Role of tissue expansion in abdominal wall reconstruction: a systematic evidence-based review. J Plast Reconstr Aesthet Surg 2017;70:741-51.

12. Jankovic J, Brin MF. Therapeutic uses of botulinum toxin. N Engl J Med 1991;324:1186-94.

13. Cakmak M, Caglayan F, Somuncu S, Leventoglu A, Ulusoy S, et al. Effect of paralysis of the abdominal wall muscles by botulinum A toxin to intraabdominal pressure: an experimental study. J Pediatr Surg 2006;41:821-5.

14. Ibarra-Hurtado TR, Nuño-Guzmán CM, Echeagaray-Herrera JE, Robles-Vélez E, De Jesús González-Jaime J. Use of botulinum toxin type A before abdominal wall hernia reconstruction. World J Surg 2009;33:2553-6.

15. Jankovic J, Albanese A, Atassi MZ, Dolly JO, Hallet M, Mayer NH. Botulinum Toxin: Therapeutic Clinical Practice and Science. Philadelphia: Saunders Elsevier; 2009. p. 512.

16. Ibarra-Hurtado TR, Nuño-Guzmán CM, Miranda-Díaz AG, Troyo-Sanromán R, Navarro-Ibarra R, et al. Effect of botulinum toxin type A in lateral abdominal wall muscles thickness and length of patients with midline incisional hernia secondary to open abdomen management. Hernia 2014;18:647-52.

17. Zendejas B, Khasawneh MA, Srvantstyan B, Jenkins DH, Schiller HJ, et al. Outcomes of chemical component paralysis using botulinum toxin for incisional hernia repairs. World J Surg 2013;37:28307.

18. Farooque F, Jacombs AS, Roussos E, Read JW, Dardano AN, et al. Preoperative abdominal muscle elongation with botulinum toxin A for complex incisional ventral hernia repair. ANZ J Surg 2016;86:79-83.

19. Rodriguez-Acevedo O, Elstner KE, Jacombs ASW, Read JW, Martins RT, et al. Preoperative botulinum toxin A enabling defect closure and 
laparoscopic repair of complex ventral hernia. Surg Endosc 2018;32:831-9.

20. Bueno-Lledó J, Torregrosa A, Jiménez R, Pastor PG. Preoperative combination of progressive pneumoperitoneum and botulinum toxin type A in patients with loss of domain hernia. Surg Endosc 2018;32:3599-608.

21. Bueno-Lledó J, Torregrosa-Gallud A. Preoperative botulinum toxin and progressive pneumoperitoneum are useful in the treatment of large incisional hernias. Am Surg 2019;85:e189-92.

22. Elstner KE, Read JW, Saunders J, Cosman PH, Rodriguez-Acevedo O, et al. Selective muscle botulinum toxin A component paralysis in complex ventral hernia repair. Hernia 2020;24:287-93.

23. Nielsen M, Bjerg J, Dorfelt A, Jørgensen LN, Jensen KK. Short-term safety of preoperative administration of botulinum toxin A for the treatment of large ventral hernia with loss of domain. Hernia 2020;24:295-9.

24. Chan DL, Ravindran P, Fan HS, Elstner KE, Jacombs ASW, et al. Minimally invasive Venetian blinds ventral hernia repair with botulinum toxin chemical component separation. ANZ J Surg 2020;90:67-71.

25. Scaglione F. Conversion ratio between botox ${ }^{\circledR}$, dysport ${ }^{\circledR}$, and xeomin ${ }^{\circledR}$ in clinical practice. Toxins (Basel) 2016;8.

26. Booth JH, Garvey PB, Baumann DP, Selber JC, Nguyen AT, et al. Primary fascial closure with mesh reinforcement is superior to bridged mesh repair for abdominal wall reconstruction. J Am Coll Surg 2013;217:999-1009.

27. Cobb WS, Burns JM, Kercher KW, Matthews BD, James Norton H, et al. Normal intraabdominal pressure in healthy adults. J Surg Res $2005 ; 129: 231-5$.

28. Ramirez OM, Ruas E, Dellon AL. "Components separation" method for closure of abdominal-wall defects: an anatomic and clinical study. Plast Reconstr Surg 1990;86:519-26.

29. Novitsky YW, Elliott HL, Orenstein SB, Rosen MJ. Transversus abdominis muscle release: a novel approach to posterior component separation during complex abdominal wall reconstruction. Am J Surg 2012;204:709-16.

30. Eleopra R, Tugnoli V, De Grandis D. The variability in the clinical effect induced by botulinum toxin type A: the role of muscle activity in humans. Mov Disord 1997;12:89-94.

31. Tomazini Martins R, Elstner KE, Skulina C, Rodriguez-Acevedo O, Read JW, et al. Limitations of electromyography in the assessment of abdominal wall muscle contractility following botulinum toxin a injection. Front Surg 2019;6:16.

32. Yiannakopoulou E. Serious and long-term adverse events associated with the therapeutic and cosmetic use of botulinum toxin. Pharmacology 2015;95:65-9.

33. Chertow DS, Tan ET, Maslanka SE, Schulte J, Bresnitz EA, et al. Botulism in 4 adults following cosmetic injections with an unlicensed, highly concentrated botulinum preparation. JAMA 2006;296:2476-9.

34. Scott AB, Suzuki D. Systemic toxicity of botulinum toxin by intramuscular injection in the monkey. Mov Disord 1988;3:333-5.

35. Herrero BA, Ecklund AE, Spencer Streett C, Ford DF, King JK. Experimental botulism in monkeys-A clinical pathological study. Exp Mol Pathol 1967;6:84-95. 